\title{
Determination of lead isotope compositions of geological samples using femtosecond laser ablation MC-ICPMS
}

\author{
YUAN HongLin ${ }^{*}$, CHEN KaiYun, BAO ZhiAn, ZONG ChunLei, DAI MengNing, \\ FAN Chao \& YIN Cong
}

State Key Laboratory of Continental Dynamics, Department of Geology, Northwest University, Xi'an 710069, China

Received January 11, 2013; accepted February 18, 2013; published online June 24, 2013

\begin{abstract}
Lead isotopic compositions of international silicate glasses, feldspar and copper-based samples are obtained using femtosecond laser ablation multiple collector inductively coupled plasma mass spectrometry (fLA-MC-ICPMS). Some international glass standards for the microanalysis are applied to evaluate the method reported here. The $\mathrm{Pb}$ isotopic composition of these NIST glasses (SRM 610, 612, 614), USGS (BHVO-2G, BCR-2G, BIR-1G and GSD-1G) and MPI-DING glasses (GOR132-G, KL2-G, T1-G, StHs60/80-G) agree well with recommended values in $2 \mathrm{~s}$ error. One of 15 copper-based metals is found to have homogenized $\mathrm{Pb}$ isotope data and can be used as an external calibration standard and quality control sample for chalcopyrite, ancient coins, etc., to trace the genesis of metal deposit and culture exchange among different dynasties ( GBW02137, ${ }^{208} \mathrm{~Pb} /{ }^{204} \mathrm{~Pb}=37.9661 \pm$ $\left.0.0005(2 \mathrm{~s}),{ }^{207} \mathrm{~Pb} /{ }^{204} \mathrm{~Pb}=15.5770 \pm 0.0002(2 \mathrm{~s}),{ }^{206} \mathrm{~Pb} /{ }^{204} \mathrm{~Pb}=17.7462 \pm 0.0002(2 \mathrm{~s})\right)$. We also prepared a feldspar glass to serve as the external calibration standard/QC for Pb isotope analysis using fLA-MC-ICPMS.
\end{abstract}

lead isotope, femtosecond laser ablation, MC-ICPMS, silicate glass, feldspar, copper matrix

Citation: Yuan H L, Chen K Y, Bao Z A, et al. Determination of lead isotope compositions of geological samples using femtosecond laser ablation MC-ICPMS. Chin Sci Bull, 2013, 58: 3914-3921, doi: 10.1007/s11434-013-5804-4

Lead isotopic composition is widely applied in geology and environmental research because of its tracing properties [1-5]. Thermal ionization mass spectrometry (TIMS) is the traditional way to precisely measure $\mathrm{Pb}$ isotopes in bulk rock/minerals after chemical reduction. Multiple-collector inductively coupled plasma mass spectrometry (MCICPMS), which is more efficient than TIMS, is the alternative method for measuring $\mathrm{Pb}$ isotopes [6-9]. The MCICPMS technique combines advantages of both TIMS (multiple collectors) and ICP (high temperature, high ionization efficiency), and this method can obtain isotopes under atmosphere, which is suitable for in situ sampling techniques such as laser ablation [10]. Combined with mass fractionation calibration with Tl solution, the MC-ICPMS technique could obtain lead isotopes as precisely as isotope dilution (ID)-TIMS [7,8,11-18].

LA-MC-ICPMS has recently developed fairly quickly

*Corresponding author (email: sklcd@nwu.edu.cn) because of its in situ microanalysis of isotope compositions. However, there are some obstacles to this technique, such as elemental fractionation during laser ablation and mass discrimination during the ion transfer from the ion source (ICP) to detectors in the mass spectrometer $[7,8,11]$. Recent studies have shown that shorter laser pulse width (from nanosecond to femtosecond) could eliminate the elemental fractionation during laser ablation, and simultaneous sampling of $\mathrm{Tl}$ could calibrate the mass discrimination of the mass spectrometer. The fLA-MC-ICPMS can measure $\mathrm{Pb}$ isotopic compositions from inclusions, minerals, glasses, metals, etc. due to its negligible elemental fractionation and wellcorrected mass discrimination [3,10,19-30].

In the present work, we have measured $\mathrm{Pb}$ isotopic compositions of copper-based metals, silicate glasses and feldspar using fLA-MC-ICPMS. The instrumental conditions are investigated to eliminate the elemental fraction during laser ablation and calibrate the mass discrimination during mass spectrometer measurement. Fifteen copper-based met- 
als are chosen to evaluate the homogeneity of $\mathrm{Pb}$ isotopic compositions to select a candidate external calibration standard for laser ablation analysis of chalcopyrite, ancient coins, etc. Some international glass references (from NIST, USGS and MAINZ) for microanalysis are used to evaluate the calibration method developed in this work [7,31-35]. We also synthesized a feldspar glass to serve as an external standard or quality control sample (QC) for $\mathrm{Pb}$ isotope analysis of feldspar minerals.

\section{Experimental}

\subsection{Reagents and samples}

Acids used in this work are $\mathrm{HCl}, \mathrm{HNO}_{3}, \mathrm{HBr}$ and $\mathrm{HF}$ after sub-boiling preparation using Savillex DST-1000. High pure water is prepared using Millipore Element (18.2 $\mathrm{M} \Omega / \mathrm{cm}$, Millipore Corporation, USA)and subsequently purified by sub-boiling distillation. $\mathrm{Pb}$ and $\mathrm{Tl}$ standard solutions are NBS981 and NIST SRM997, respectively. The purity of Argon and helium gases is better than 99.9995\%.

The 11 international silicate glasses are from NIST (SRM 610, 612 and 614), USGS (BHVO-2G, BCR-2G, BIR-1G and GSD-1G), and Mainz MPI-DING (GOR132-G, KL2-G, T1-G and StHs60/80-G). The fifteen copper-based metals are from the Chinese Certified Reference Materials Research Centre, including brass (BY1902-4, GBW(E) 020012, GBW(E)020014a, BYG1902-3, GBW(E)020013), bronze (GBW02137, GBW02138, GBW02139, GBW02140), aluminum bronze (GBW02118, GBW02117), zinc cupronickel (GBW(E)020032), Tin bronze (ZQSn3-12-5), and lead brass (GBW02116, ZBY9031). A fresh K-feldspar is sampled from Qinhuangdao, Hebei.

The sample target is prepared as follows: (1) place the sample on double-stick tape, which has already been placed on a glass slide; (2) place a PVC ring around the sample (diameter $16 \mathrm{~mm}$ and height $8 \mathrm{~mm}$ ); (3) fill the PVC ring with mixed resin and place it on a hot plate or in an oven until the resin solidifies; (4) remove the glass slide and polish the sample surface; and (5) clean the sample target with ethanol, high pure water and $2 \% \mathrm{HNO}_{3}$ to remove any contamination.

\subsection{Instrumental}

All the experiments are conducted at the State Key Laboratory of Continental Dynamics, Northwest University. A MC-ICPMS (Nu PlasmaII, Nu instruments, UK) is used to measure lead isotopic compositions. The Nu Plasma II is the latest generation MC-ICPMS, which is equipped with 16 Faraday cups and 5 full-size discrete dynode multipliers for greater flexibility in terms of most isotope analysis in the periodic table. The zoom optics system enables simultaneous measurement of two or more different isotopes with great mass jump (such as $\mathrm{Hf}$ and $\mathrm{Pb}$ ) in one run. The desolvator system is an Aridus $\mathrm{II}^{\mathrm{TM}}$ (CETAC, USA; 100 uL/min PFA nebulizer), which can enhance instrumental sensitivity of MC-ICPMS greater than 10-fold while the oxide ratios are kept lower than $0.03 \%\left(\mathrm{CeO}^{+} / \mathrm{Ce}^{+}\right)$.

The femtosecond laser ablation system (NWR UP ${ }^{\mathrm{Femto}}$, ESI, USA) consists of a Ti: sapphire femtosecond laser amplifier (Integra-HE, Quantronix) and ESI optical path, sampling, viewing and a control system. The Quantronix femtosecond laser is a regenerative and multi-pass Ti: sapphire laser based on the chirped pulse amplification (CPA) technique. The output laser wavelength is $263.5 \mathrm{~nm}$ after the 3 rd harmonics of the original $795 \mathrm{~nm}$ wavelength. The energy density distribution of the laser is a Gaussian peak, and the final pulse width is less than $130 \mathrm{fs}$. The output energy is greater than $600 \mu \mathrm{J}$ (UV, $\lambda=263.5 \mathrm{~nm}, 250 \mathrm{~Hz}$ ), which represents the energy density, and the sample surface is approximately $10 \mathrm{~J} / \mathrm{cm}^{2}$. The spot size is between 1-65 $\mu \mathrm{m}$ based on 13 adjustable apertures. The sampling cell is a two-volume chamber that consists of a large, efficient sample chamber $\left(5000 \mathrm{~cm}^{3}\right)$ and a super-high-sensitivity coneshaped sample cell $\left(<0.5 \mathrm{~cm}^{3}\right.$, home-made). The instrumental parameters are summarized in Table 1 .

\subsection{Analytical method}

Samples are loaded in the holder, and the chamber is evacuated three times. Then, the sample chamber is filled with carrier gas $(\mathrm{He})$, and the gas flow rate is kept at $1 \mathrm{~L} / \mathrm{min}$ to remove any air/contamination inside the tube. The total Femtosecond laser ablation system is stabilized for $>30 \mathrm{~min}$. The optical path is filled with $\mathrm{N}_{2}$ with a flow rate of approximately $2 \mathrm{~L} / \mathrm{min}$. The energy density is approximately 6 $\mathrm{J} / \mathrm{cm}^{2}$. Some craters of NIST 610 and bronze are illustrated in Figure 1. The laser beam is deformed when the spot size is smaller than $10 \mu \mathrm{m}$ (Figure 1(a),(b)). The $2 \mu \mathrm{m}$ setup (from aperture) creates an ellipse-shaped crater with short and long axes of $2 \mu \mathrm{m}$ and $5 \mu \mathrm{m}$, respectively. The $5 \mu \mathrm{m}$ setup also results in a $5 \mu \mathrm{m}$ (short axis) $\times 8 \mu \mathrm{m}$ (long axis) ellipse-shaped crater. When the spot size is larger than 10 $\mu \mathrm{m}$, the craters are expected to be round. The deformation between the short and long axis of a $45 \mu \mathrm{m}$ crater is approximately $4.4 \%$ (Figure 1(c)), which is acceptable for any ablation application. Bronze is also ablated with a $40 \mu \mathrm{m}$ spot, and the responding crater is round (the difference between short and long axis is about $2.5 \%$, Figure $1(\mathrm{~d}))$. The deformation of small craters $(<10 \mu \mathrm{m})$ is caused by laser diffraction, and the deformation of larger craters $(>10 \mu \mathrm{m})$ is caused by the quality of the aperture system. There is no effect on general applications because the spot size is larger than $20 \mu \mathrm{m}$ for most microanalysis using a laser ablation system. However, the real spot size needs to be considered for high spatial analysis, such as fish otoliths, mineral rings, and inclusions. The crater wall of silicate glasses (Figure $1(\mathrm{a})-(\mathrm{d}))$ is not as steep as the nanosecond excimer laser 
Table 1 Instrumental operating parameters for fLA-MC-ICPMS

\begin{tabular}{|c|c|}
\hline \multicolumn{2}{|c|}{ Nu Plasma II MC-ICPMS } \\
\hline Plasma gas & $17 \mathrm{~L} / \mathrm{min} \mathrm{Ar}$ \\
\hline Auxiliary gas & $0.8 \mathrm{~L} / \mathrm{min} \mathrm{Ar}$ \\
\hline Nebulizer gas & $0.25 \mathrm{~L} / \mathrm{min} \mathrm{Ar}$ \\
\hline RF Power & $1300 \mathrm{~W}$ \\
\hline Accelerating voltage & $6010 \mathrm{~V}$ \\
\hline Cones & $\mathrm{Ni}, 1.1 \mathrm{~mm}$ sample cone, \\
\hline Sensitivity & $600 \mathrm{~V} / \mathrm{ppm}$ (dry mode) \\
\hline Integration time & SN: $30 \mathrm{~s}$ blank $+500 \mathrm{~s}$ signal, static mode \\
\hline \multicolumn{2}{|c|}{ Aridus II desolvation nebulizer system } \\
\hline Membrane temperature & $160^{\circ} \mathrm{C}$ \\
\hline Spray chamber temperature & $110^{\circ} \mathrm{C}$ \\
\hline Sweep gas flow & 3.25 L/min Ar \\
\hline Hot gas flow & 25 psi Ar \\
\hline Sample uptake rate & $100 \mu \mathrm{L} / \mathrm{min}, \mathrm{PFA}$ nebulizer \\
\hline \multicolumn{2}{|c|}{ ESI UP Femto $266 \mathrm{~nm}$ femtosecond laser ablation system } \\
\hline Laser model & Quantronix Integra-HE \\
\hline Output wavelength & $266 \mathrm{~nm}$ \\
\hline Beam profile & $>95 \%$ fit to Gaussian \\
\hline Beam diameter & $1.0 \mathrm{~mm}$ \\
\hline Pulse duration & $<130 \mathrm{fs}$ \\
\hline Output energy & $>600 \mu \mathrm{J}$ \\
\hline Energy density & $6 \mathrm{~J} / \mathrm{cm}^{2}$ \\
\hline Spot size & $1-65 \mu \mathrm{m}$ \\
\hline Frequency & $1-50,125,250 \mathrm{~Hz}$ \\
\hline Sample cell & Two-volume cell \\
\hline Carrier gas flow & $\mathrm{He}, 0.9 \mathrm{~L} / \mathrm{min}$ \\
\hline
\end{tabular}

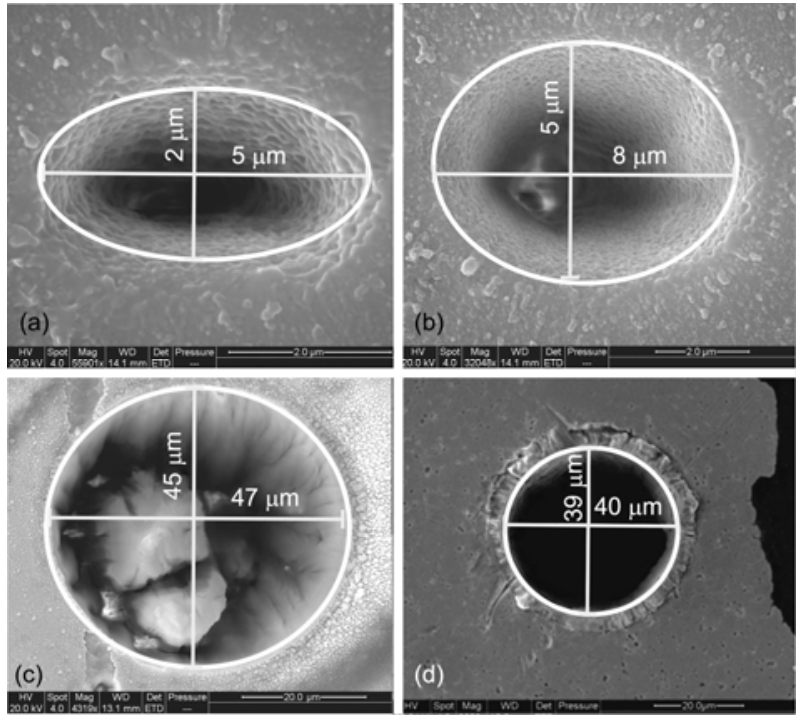

Figure 1 Scanning electron microscope images of laser ablated craters. (a)-(c) NIST SRM 610, responding to 2, 5, and $45 \mu \mathrm{m}$ aperture setup; (d) bronze, the laser spot is $40 \mu \mathrm{m}$.

and the crater walls in metals (Figure 1(d)), and there are some islands inside large craters $(>20 \mu \mathrm{m}$, Figure 1(c)) because of the energy distribution of the aperture system. These islands will affect the sensitivity of the following mass spectrometer, and the intensity will drop quickly in TRA mode using single spot analysis on silicate glasses. This work utilizes the line scan mode to avoid this disadvantage.

The MC-ICPMS is optimized after $30 \mathrm{~min}$ stabilization using a lead isotope standard solution (NBS 981) and a thallium solution (NBS 997) sampled through a desolvator (Aridus II). The instrumental setup is shown in Figure 2. The isotopes measured in this work are ${ }^{202} \mathrm{Hg},{ }^{203} \mathrm{Tl},{ }^{204} \mathrm{~Pb}+$ $\mathrm{Hg},{ }^{205} \mathrm{Tl},{ }^{206} \mathrm{~Pb},{ }^{207} \mathrm{~Pb}$ and ${ }^{208} \mathrm{~Pb}$ (Table 2). The resistors of all Faraday cups are $10^{11} \Omega$. The ${ }^{204} \mathrm{Hg}$ interference on ${ }^{204} \mathrm{~Pb}$ can be subtracted using ${ }^{204} \mathrm{Hg} /{ }^{202} \mathrm{Hg}=0.229883$. The backgrounds of $\mathrm{Pb}$ and $\mathrm{Hg}$ are $10 \mathrm{ng} / \mathrm{L}$ and $20 \mathrm{pg} / \mathrm{L}$, respectively. The intensities of these backgrounds are within the electronic noise background of Faraday cups and will not affect the $\mathrm{Pb}$ isotope measurement of samples that contain $\mathrm{Pb}$ contents higher than $1 \mu \mathrm{g} / \mathrm{g}$. The mass discrimination of $\mathrm{Pb}$ can be calibrated using $\mathrm{Tl}$, which is mixed with aerosols before entering the torch (Figure 2). The instrument optimization criteria are high sensitivity, low oxide ratios, low double charge ratios, reliable and stable isotopic compositions. The isolate valve behind the skimmer cone is closed when the optimization is completed and ready for preamplifier calibration. The laser is kept on, ablating some samples to initialize the cones. Tl solution is kept on during all sections, and the background of the $\mathrm{Tl}$ utilizes the one before analysis because the background is fairly stable. Otherwise, the analytical efficiency will decrease at least three times due to the wash time (after analysis) and sampling time (before analysis), which take about $200 \mathrm{~s}$, while the analysis of samples takes only $30 \mathrm{~s}$ for background plus 40-60 s of signal. The intensity of $\mathrm{Tl}$ drops when the laser generated aerosol enters the plasma [10]; however, there is no effect on the mass discrimination of $\mathrm{Tl}$ [36].

MC-ICPMS works in TRA (Time-Resolved Analysis) mode. The integration time is approximately $0.2 \mathrm{~s}$, and the scanning speed is $5 \mu \mathrm{m} / \mathrm{s}$. The sampling area is $\sim 200 \mu \mathrm{m} \times$ $30 \mu \mathrm{m}$ or $\sim 80 \mu \mathrm{m} \times 80 \mu \mathrm{m}$, and the depth is less than $15 \mu \mathrm{m}$. The laser frequency and spot size are chosen depending on the $\mathrm{Pb}$ content of samples. For high $\mathrm{Pb}$ concentrations (for example, bronze), the laser frequency is set to $5-10 \mathrm{~Hz}$, and the spot size is set to $30 \mu \mathrm{m}$. For low $\mathrm{Pb}$ contents (feldspar), the laser frequency is set to $125-250 \mathrm{~Hz}$, and the spot size is set up to $50 \mu \mathrm{m}$ to obtain higher $\mathrm{Pb}$ intensities. NIST 610 served as the external standard and quality control sample to monitor the reliability of $\mathrm{Pb}$ isotopic compositions.

\section{Results and discussion}

\subsection{Data calibration}

Five different calibration methods are evaluated in this work: (1) sample-standard bracketing technique (SSB, NIST SRM612 served as standard); (2) calibrating mass discrimination with factors calculated from $\mathrm{Tl}$ after power law (assuming $\alpha_{\mathrm{Tl}}=\alpha_{\mathrm{Pb}}$ ); (3) calibrating mass discrimination with 


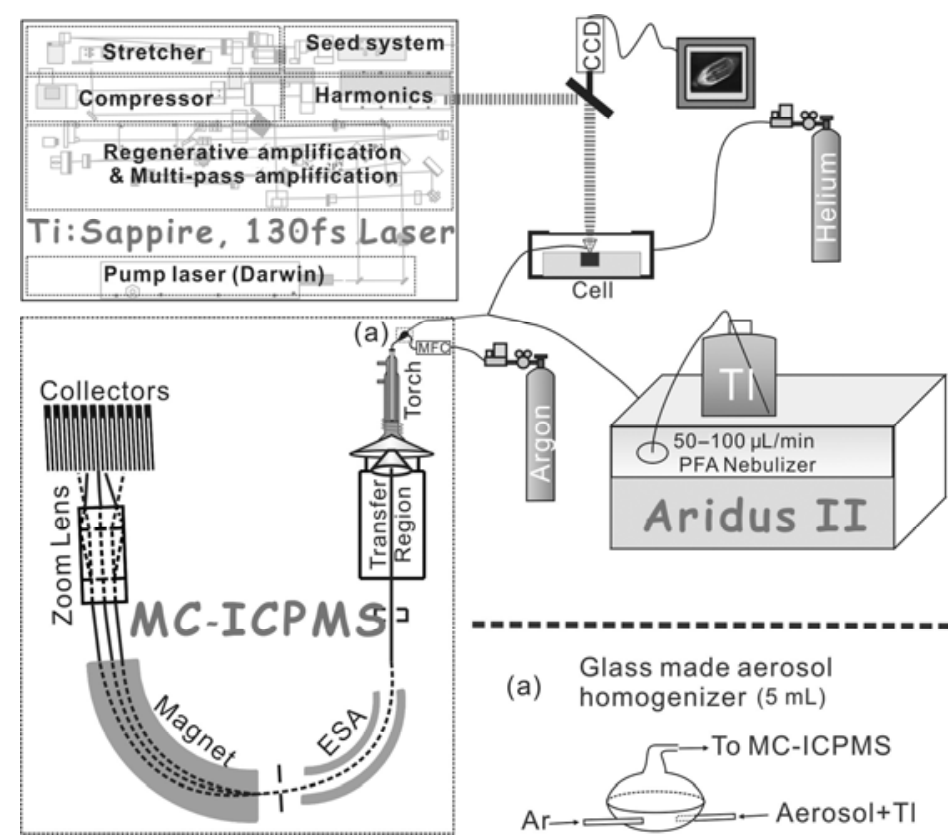

Figure 2 Schematic diagram of desolvator + fLA-MC-ICPMS. Tl dry aerosol (aspiring through Aridus II) mixes with the laser generated aerosol before the torch and then mixes with argon in a home-made aerosol homogenizer (a).

Table 2 Alignment of Faraday cups array for Hg-Tl-Pb isotope analysis of MC-ICPMS (Nu Plasma II)

\begin{tabular}{cccccccccc}
\hline Faraday cups & F13 & F12 & F11 & F10 & F9 & F8 & F7 & F6 & F5 \\
\hline Position & 4 & 3 & 2 & 1 & 0 & -1 & -2 & -3 & -4 \\
Mass & 200 & 201 & 202 & 203 & 204 & 205 & 206 & 207 & 208 \\
Isotope & ${ }^{200} \mathrm{Hg}$ & ${ }^{201} \mathrm{Hg}$ & ${ }^{202} \mathrm{Hg}$ & ${ }^{203} \mathrm{Tl}$ & ${ }^{204} \mathrm{Hg}+{ }^{204} \mathrm{~Pb}$ & ${ }^{205} \mathrm{Tl}$ & ${ }^{206} \mathrm{~Pb}$ & ${ }^{207} \mathrm{~Pb}$ & ${ }^{208} \mathrm{~Pb}$ \\
\hline
\end{tabular}

factors calculated from $\mathrm{Tl}$ after power law (considering the mass discrimination between $\mathrm{Pb}$ and $\mathrm{Tl}, \alpha_{\mathrm{Tl}=} a \times \alpha_{\mathrm{Pb}}$, a is the difference that can be obtained using standard isotope solution NBS 981(Pb) and 997(Tl)); (4) calibrating mass discrimination with factors calculated from $\mathrm{Tl}$ after exponential law (assuming $\alpha_{\mathrm{Tl}}=\alpha_{\mathrm{Pb}}$ ); and (5) calibrating mass discrimination with factors calculated from $\mathrm{Tl}$ after power law $\left(\alpha_{\mathrm{Tl}=} a \times \alpha_{\mathrm{Pb}}\right.$, see (2)). The results from both methods (3) and (5) agree with recommended values [7] in 2 s error, whereas method (3) is more reliable and agrees with isotope dilution (ID)-TIMS in $2 \mathrm{~s}$ error (Figure 3). We use method (3) in this work. For more details of the calibration method, see [36].

\subsection{Laser ablation conditions}

The laser energy density affects the materials ablated; therefore, the signal intensity is seriously controlled by laser energy density. However, the increase of laser energy cannot always gain higher sensitivity because some materials in the middle of crater cannot be ablated, which is most likely caused by laser diffraction based on current optical path design. We find that the signal intensity remains similar when the laser energy density is larger than $8 \mathrm{~J} / \mathrm{cm}^{2}$, where-

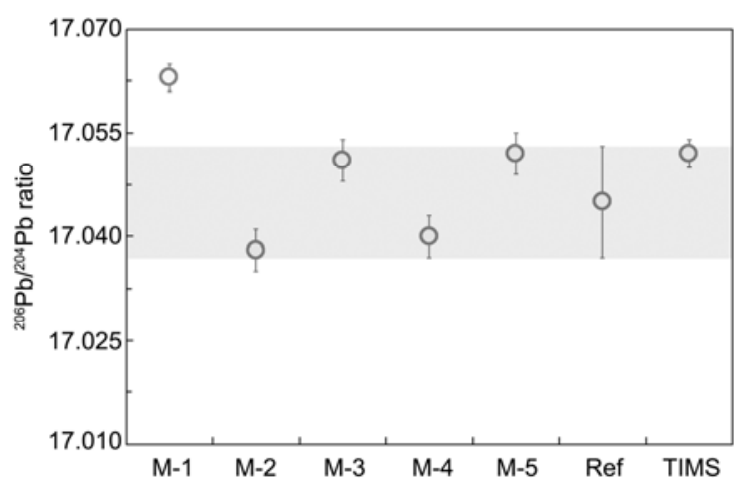

Figure $3{ }^{206} \mathrm{~Pb} /{ }^{204} \mathrm{~Pb}$ ratios among different calibration methods. M- $x$ ( $x: 1-5)$ : different calibration methods; Ref: published values [40]; TIMS: ratios measured by TIMS [7].

as the $\mathrm{Pb}$ isotopic compositions agree well with $2 \mathrm{~s}$ error for different laser energy densities. We also find that the laser frequency has no effect on the accuracy of $\mathrm{Pb}$ isotopic compositions. However, the intensity affects measurement precision because the uncertainty of detectors is negatively correlated with signal intensity. We use $6 \mathrm{~J} / \mathrm{cm}^{2}$ (energy), $30-50 \mu \mathrm{m}$ (spot size) and 10-250 Hz (laser frequency) in this work. He is used as the carrier gas because it promotes 
sensitivity (up to 50\%) and decreases the mass discrimination difference between $\mathrm{Pb}$ and $\mathrm{Tl}$ by approximately $20 \%$ $\left(\right.$ Ar: $\beta_{\mathrm{Tl}}=-1.604, \beta_{\mathrm{Pb}}=-1.632 ; \mathrm{He}: \beta_{\mathrm{Tl}}=-1.337, \beta_{\mathrm{Pb}}=$ $-1.346)[36]$.

\subsection{Copper-based samples}

Fifteen copper-based metals are selected for evaluation of $\mathrm{Pb}$ isotopic compositions (Table 3). The copper contents of these samples range from $60 \%$ to $85 \%$, and $\mathrm{Pb}$ concentrations range from $0.017 \%$ to $17.62 \%$. There are six types of samples in the form of chips and grain: brass, bronze, aluminum bronze, zinc cupronickel, tin bronze and lead brass.

All the copper-based metals are measured four times using $40 \mu \mathrm{m}$ spot size, $5 \mu \mathrm{m} / \mathrm{s}$ line scan speed and $5 \mathrm{~Hz}$ laser frequency. The relative standard deviation (RSD) of these samples is listed in Figure 4. The RSDs of CUPB12, 13, 15 and 14 are smaller than the others, and CUPB12 (GBW02137) is the most homogeneous metal of all fifteen samples because it has the smallest RSD $(<0.01 \%)$. To obtain accurate and precise $\mathrm{Pb}$ isotopic compositions and to evaluate the accuracy of the fLA-MC-ICPMS method, the $\mathrm{Pb}$ of CUPB12-15 metals is purified by chromatography separation (AG1-X8, BioRad, 200-400 mesh) after high temperature bomb digestion [37,38]. Some USGS standards are also measured together with the metals (Table 4). $\mathrm{Pb}$ isotopic compositions of NBS 981 and NOD-A-1 agree with published values in $2 \mathrm{~s}$, whereas AGV-2 shows slightly offset from results of Baker et al. [7]. However, the

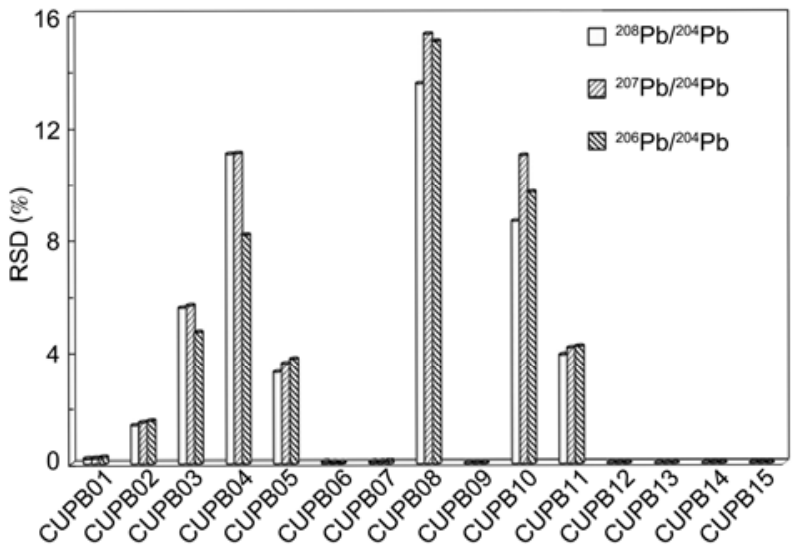

Figure 4 Relative standard deviations of $\mathrm{Pb}$ isotopic compositions of 15 copper-based metals $(n=4)$

relativeerrors of all ${ }^{208} \mathrm{~Pb} /{ }^{204} \mathrm{~Pb},{ }^{207} \mathrm{~Pb} /{ }^{204} \mathrm{~Pb}$ and ${ }^{206} \mathrm{~Pb} /{ }^{204} \mathrm{~Pb}$ ratios are less than $0.05 \%$.

GUPB12-15 is also measured using fLA-MC-ICPMS, and NIST SRM 610 is used as QC (Table 5). The results of NIST 610 agree well with ID-TIMS data [39] in $2 \mathrm{~s}$. The analytical error of laser ablation is 10 times higher than solution data, and the accuracy remains reliable. $\mathrm{Pb}$ isotopic data of both solution and laser ablation of CUPB12 agree with each other in $2 \mathrm{~s}$. Relative errors between solution and laser ablation of ${ }^{208} \mathrm{~Pb} /{ }^{204} \mathrm{~Pb},{ }^{207} \mathrm{~Pb} /{ }^{204} \mathrm{~Pb}$ and ${ }^{206} \mathrm{~Pb} /{ }^{204} \mathrm{~Pb}$ are $0.00079 \%, 0.013 \%$ and $0.0023 \%$, respectively. $\mathrm{Pb}$ isotope data of solution separation of CUPB13-15 show slight

Table 3 Name and identification code of copper-based metals

\begin{tabular}{|c|c|c|c|c|c|}
\hline $\begin{array}{l}\text { Experimental } \\
\text { ID }\end{array}$ & Type & $\begin{array}{l}\text { Ref. ID } \\
\text { code }\end{array}$ & $\begin{array}{c}\text { Experimental } \\
\text { ID }\end{array}$ & Type & $\begin{array}{l}\text { Ref. ID } \\
\text { code }\end{array}$ \\
\hline CUPB01 & Brass & BY1902-4 & CUPB09 & Tin bronze & ZQSn3-12-5 \\
\hline CUPB02 & Brass & GBW(E)020012 & CUPB10 & Aluminum bronze & GBW02117 \\
\hline CUPB03 & Brass & GBW(E)020014a & CUPB11 & Zinc cupronickel & GBW(E)020032 \\
\hline CUPB04 & Brass & BYG1902-3 & CUPB12 & Bronze & GBW02137 \\
\hline CUPB05 & Brass & GBW(E)020013 & CUPB13 & Bronze & GBW02138 \\
\hline CUPB06 & Lead brass & GBW02116 & CUPB14 & Bronze & GBW02139 \\
\hline CUPB08 & Aluminum bronze & GBW02118 & & & \\
\hline
\end{tabular}

Table $4 \mathrm{~Pb}$ isotopic composition of USGS standards and copper-based metals using chemical digestion MC-ICPMS ${ }^{\text {a) }}$

\begin{tabular}{|c|c|c|c|c|c|c|}
\hline & \multicolumn{2}{|c|}{${ }^{208} \mathrm{~Pb} /{ }^{204} \mathrm{~Pb}$} & \multicolumn{2}{|c|}{${ }^{207} \mathrm{~Pb} /{ }^{204} \mathrm{~Pb}$} & \multicolumn{2}{|c|}{${ }^{206} \mathrm{~Pb} /{ }^{204} \mathrm{~Pb}$} \\
\hline & Ratio & $2 \mathrm{~s}$ & Ratio & $2 \sigma$ & Ratio & $2 \mathrm{~s}$ \\
\hline NBS981 & 36.7260 & 0.0007 & 15.4993 & 0.0003 & 16.9456 & 0.0003 \\
\hline Ref* & 36.7265 & 0.0019 & 15.5000 & 0.0006 & 16.9418 & 0.0006 \\
\hline Ref* $^{*}$ & 38.552 & 0.010 & 15.621 & 0.003 & 18.873 & 0.005 \\
\hline NOD-A-1 & 38.9594 & 0.0005 & 15.6859 & 0.0002 & 18.9649 & 0.0002 \\
\hline Ref* & 38.956 & 0.003 & 15.685 & 0.001 & 18.964 & 0.001 \\
\hline CUPB12 & 37.9661 & 0.0005 & 15.5770 & 0.0002 & 17.7462 & 0.0002 \\
\hline CUPB13 & 38.1042 & 0.0008 & 15.5842 & 0.0003 & 17.8452 & 0.0003 \\
\hline CUPB14 & 38.1245 & 0.0005 & 15.5836 & 0.0002 & 17.8739 & 0.0002 \\
\hline CUPB15 & 38.2250 & 0.0006 & 15.5894 & 0.0002 & 17.9513 & 0.0003 \\
\hline
\end{tabular}


Table 5 Pb isotopic compositions of CUPB12-15 and NIST SRM 610 using fLA-MC-ICPMS ${ }^{\text {a) }}$

\begin{tabular}{|c|c|c|c|c|c|c|}
\hline & \multicolumn{2}{|c|}{${ }^{208} \mathrm{~Pb} /{ }^{204} \mathrm{~Pb}$} & \multicolumn{2}{|c|}{${ }^{207} \mathrm{~Pb} /{ }^{204} \mathrm{~Pb}$} & \multicolumn{2}{|c|}{${ }^{206} \mathrm{~Pb} /{ }^{204} \mathrm{~Pb}$} \\
\hline & Ratio & $2 \mathrm{~s}$ & Ratio & $2 \mathrm{~s}$ & Ratio & $2 \mathrm{~s}$ \\
\hline${\text { CUPB } 12^{\mathrm{b})}}$ & 37.9664 & 0.0004 & 15.5791 & 0.0002 & 17.7466 & 0.0002 \\
\hline CUPB13 & 38.107 & 0.006 & 15.588 & 0.002 & 17.849 & 0.002 \\
\hline CUPB14 & 38.123 & 0.005 & 15.586 & 0.002 & 17.877 & 0.002 \\
\hline CUPB15 & 38.115 & 0.004 & 15.583 & 0.001 & 17.875 & 0.002 \\
\hline NIST610 & 36.968 & 0.007 & 15.512 & 0.003 & 17.051 & 0.003 \\
\hline Ref* & 36.964 & 0.022 & 15.504 & 0.009 & 17.045 & 0.008 \\
\hline
\end{tabular}

a) ${ }^{205} \mathrm{Tl} /{ }^{203} \mathrm{Tl}=2.38890$. b) $n=112$. * Reference values of NIST SRM 610 are cited from $[7,39]$.

deviation from laser ablation. Relative errors of ${ }^{206} \mathrm{~Pb} /{ }^{204} \mathrm{~Pb}$ of CUPB13, 14 and 15 (solution vs. laser ablation) are $0.021 \%, 0.017 \%$ and $0.4 \%$, respectively. A total of 112 measurements of CUPB12 are performed, and the RSDs of ${ }^{208} \mathrm{~Pb} /{ }^{204} \mathrm{~Pb},{ }^{207} \mathrm{~Pb} /{ }^{204} \mathrm{~Pb}$ and ${ }^{206} \mathrm{~Pb} /{ }^{204} \mathrm{~Pb}$ are $0.0011 \%$, $0.0013 \%$ and $0.0012 \%$, respectively. Based on the $\mathrm{Pb}$ isotopic composition from both laser ablation and solution, CUPB12 is selected as QC for in situ microanalysis of $\mathrm{Pb}$ isotopes in copper-based samples.

\subsection{Measurement of USGS and MPI-DING reference glasses}

Eleven USGS and MPI-DING reference glasses with lead concentrations ranging from 1.7 to $413 \mu \mathrm{g} / \mathrm{g}$ are measured using the femtosecond laser ablation MC-ICPMS method with a modified data processing $\left({ }^{205} \mathrm{Tl} /{ }^{203} \mathrm{Tl}\right.$ optimization $)$ procedure to evaluate the method setup in this work. The measured Pb isotopic compositions of the NIST SRM 610, 612 and 614; USGS reference glasses BHVO-2G, BCR-2G, GSD-1G and BIR-1G; and the MPI-DING reference glasses GOR132-G, KL2-G, T1-G and StHs60/80-G are in good agreement with the recommended or reference values with $2 \sigma$ error. ${ }^{208} \mathrm{~Pb} /{ }^{204} \mathrm{~Pb},{ }^{207} \mathrm{~Pb} /{ }^{204} \mathrm{~Pb},{ }^{206} \mathrm{~Pb} /{ }^{204} \mathrm{~Pb}$, and ${ }^{207} \mathrm{~Pb} /{ }^{206} \mathrm{~Pb}$ ratios in the NIST, USGS and MPI-DING reference glasses obtained in this work are compared with recommended values and show linear fit better than 0.99 (Figure 5). We also obtained the first high-precision $\mathrm{Pb}$ isotopic data for GSE-1G, GSC-1G, GSA-1G and CGSG (CGSG-1, CGSG-2, CGSG-4 and CGSG-5) reference glasses using the femtosecond laser ablation MC-ICPMS analysis technique (Figure 6). For detailed discussion, see [36].

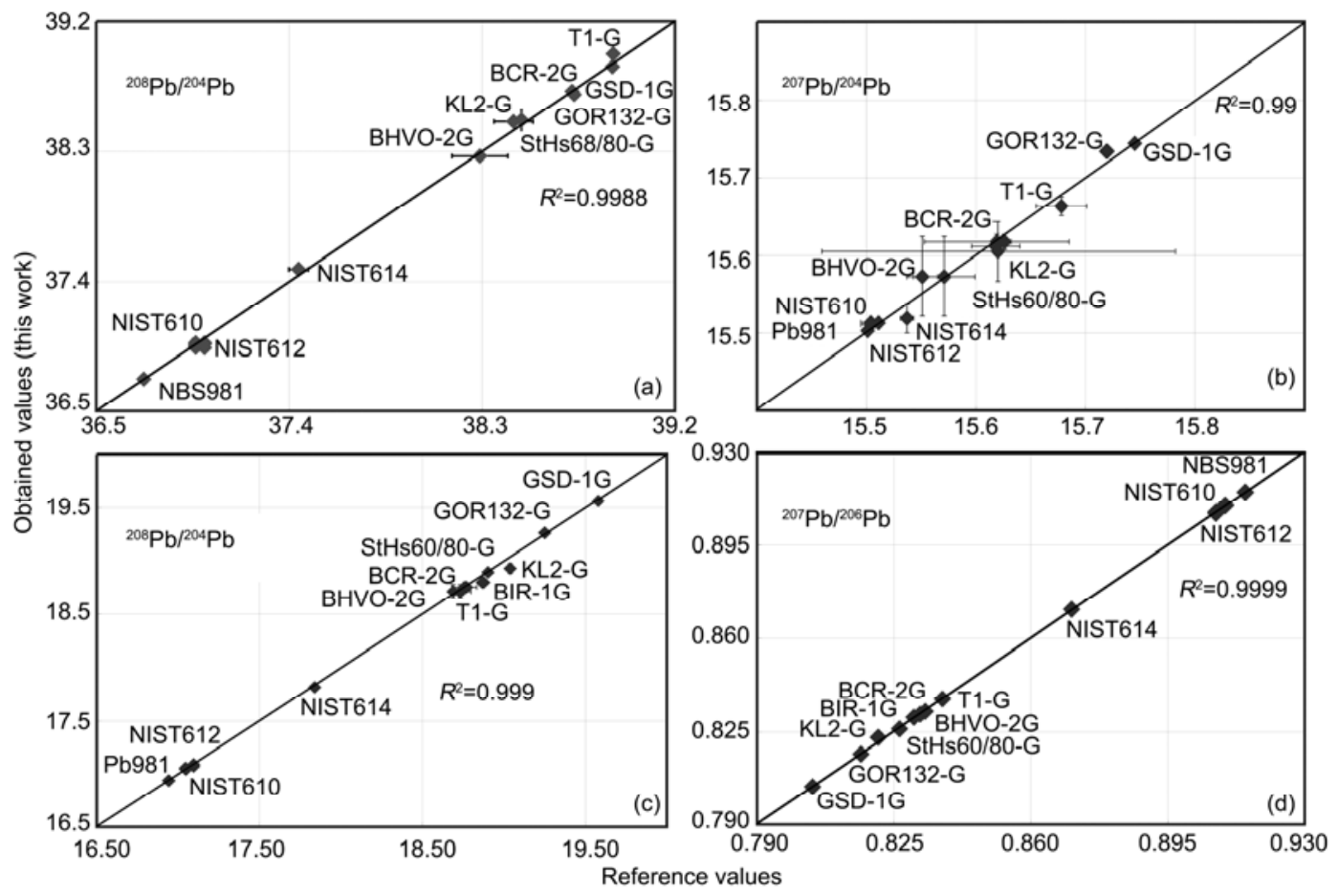

Figure 5 Reference values and obtained values (this work) for the ${ }^{208} \mathrm{~Pb} /{ }^{204} \mathrm{~Pb},{ }^{207} \mathrm{~Pb} /{ }^{204} \mathrm{~Pb},{ }^{206} \mathrm{~Pb} /{ }^{204} \mathrm{~Pb}$, and ${ }^{207} \mathrm{~Pb} /{ }^{206} \mathrm{~Pb}$ ratios in the NIST, USGS, and MPI-DING reference glasses. The plot exhibits a good linear fit $\left(R^{2}>0.99\right)$. The error bars are $\pm 2 \sigma$. The Pb isotopic reference values for the NIST reference materials $(610,612$ and 614) were obtained from Jochum and Brueckuer [39], and the other reference values were obtained from the GeoRem database (http://georem.mpch-mainz.gwdg.de/) [40]. 
Table $6 \mathrm{~Pb}$ isotopic composition of synthesized feldspar glass

\begin{tabular}{|c|c|c|c|c|c|c|}
\hline & \multicolumn{2}{|c|}{${ }^{208} \mathrm{~Pb} /{ }^{204} \mathrm{~Pb}$} & \multicolumn{2}{|c|}{${ }^{207} \mathrm{~Pb} /{ }^{204} \mathrm{~Pb}$} & \multicolumn{2}{|c|}{${ }^{206} \mathrm{~Pb} /{ }^{204} \mathrm{~Pb}$} \\
\hline & Ratio & $2 \mathrm{~s}$ & Ratio & $2 \mathrm{~s}$ & Ratio & $2 \mathrm{~s}$ \\
\hline SN & 39.8699 & 0.0006 & 15.8764 & 0.0002 & 20.9090 & 0.0002 \\
\hline fLA $(n=31)$ & 39.8770 & 0.0016 & 15.8753 & 0.0005 & 20.9066 & 0.0011 \\
\hline
\end{tabular}

\subsection{Pb isotopic composition of synthesized feldspar glass}

Feldspar is one of the common rock-forming minerals with low U-Th and relatively high common $\mathrm{Pb}$ concentrations. $\mathrm{Pb}$ isotopic compositions of feldspar could be applied in geology for mapping gross crustal structure or magmatic evolution. The traditional way to obtain $\mathrm{Pb}$ isotopes utilizes both a leaching technique and a dissolution method. The fLA-MC-ICPMS can analyze $\mathrm{Pb}$ isotopes with spatial resolution, but it suffers from rare matrix-matched standards to control the data quality. We prepared a synthesized feldspar glass (melting well grinded fresh K-feldspar powder (3000 mesh) doped with $\mathrm{PbSiO}_{3}$ in a high temperature oven at $1650^{\circ} \mathrm{C}$ and quenched in liquid $\mathrm{N}_{2}$ ) to serve as an external standard or QC. $\mathrm{Pb}$ isotopic compositions between the chemical chromatography separation method and the fLA-MC-ICPMS technique agree well with each other (Table 6). The relative errors (RE) of ${ }^{208} \mathrm{~Pb} /{ }^{204} \mathrm{~Pb},{ }^{207} \mathrm{~Pb} /{ }^{204} \mathrm{~Pb}$ and ${ }^{206} \mathrm{~Pb} /{ }^{204} \mathrm{~Pb}$ are $0.018 \%, 0.0069 \%$ and $0.012 \%$, respectively. This glass can be utilized for instrumental optimization, conditioning the cones before sample measurement. It can also serve as a matrix-matched external standard or QC during sample analysis.

\section{Conclusion}

$\mathrm{Pb}$ isotopic compositions of samples with different matrices can be obtained using fLA-MC-ICPMS after mass discrimination, which is performed using Tl solution with the power law and correcting the mass discrimination difference between $\mathrm{Pb}$ and $\mathrm{Tl}$. The agreement of $\mathrm{Pb}$ isotope microanalysis data for thirteen international glass standards between this work and recommended values reveals that this analytical method is reliable.

A bronze standard (GBW02137) is selected from fifteen copper-based standards on the basis of $\mathrm{Pb}$ isotope homogeneity $\left({ }^{208} \mathrm{~Pb} /{ }^{204} \mathrm{~Pb}=37.9661 \pm 0.0005(2 \mathrm{~s}) ;{ }^{207} \mathrm{~Pb} /{ }^{204} \mathrm{~Pb}=\right.$ $15.5770 \pm 0.0002(2 \mathrm{~s}) ;{ }^{206} \mathrm{~Pb} /{ }^{204} \mathrm{~Pb}=17.7462 \pm 0.0002(2$ $\mathrm{s})$ ). The results of solution digestion and laser ablation (112 runs) agree well with each other. This standard can serve as an external standard or QC for copper-based samples, for example chalcopyrite, ancient coins, etc.

We also synthesized a feldspar glass by melting well grinded fresh K-feldspar (3000 mesh) in a high temperature oven $\left(1650^{\circ} \mathrm{C}\right)$. The results of laser ablation agree with those of solution digestion. This glass can potentially be utilized in $\mathrm{Pb}$ isotope measurement of feldspar minerals for a matrix-matched external calibration material or QC purpose.

We are grateful to Jochum $K P$ and Zhan Xiuchun for provision of MPI-DING glasses and CGSG glasses, and to two anonymous referees for helpful comments on the text. This work was supported by the National Natural Science Foundation of China (40973011), the State Key Laboratory of Independent Research Key Topics of Special Funds from the Ministry of Science and Technology (CJ11070), and the MOST Research Foundation from the State Key Laboratory of Continental Dynamics.

1 Gagnevin $\mathrm{D}$, Daly $\mathrm{J} \mathrm{S}$, Waight $\mathrm{T} \mathrm{E}$, et al. $\mathrm{Pb}$ isotopic zoning of K-feldspar megacrysts determined by Laser Ablation Multi-Collector ICP-MS: Insights into granite petrogenesis. Geochim Cosmochim Acta, 2005, 69: 1899-1915

2 Tyrrell S, Haughton P D W, Daly J S. Drainage reorganization during breakup of Pangea revealed by in-situ $\mathrm{Pb}$ isotopic analysis of detrital K-feldspar. Geology, 2007, 35: 971-974

3 Tyrrell S, Haughton P D W, Souders A K, et al. Large-scale, linked drainage systems in the NW European Triassic: Insights from the Pb isotopic composition of detrital K-feldspar. J Geol Soc Lond, 2012, 169: 279-295

4 Aleinikoff J N, Muhs D R, Bettis E A, et al. Isotopic evidence for the diversity of late Quaternary loess in Nebraska: Glaciogenic and nonglaciogenic sources. Geol Soc Am Bull, 2008, 120: 1362-1377

5 Burnett A, Kurtz A C, Brabander D, et al. Dendrochemical record of historical lead contamination sources, Wells G\&H Superfund Site, Woburn, Massachusetts. J Environ Qual, 2007, 36: 1488-1494

6 Albarede F, Beard B. Analytical methods for Non-traditional Isotopes. In: Rosso J J, ed. Reviews in Mineralogy and Geochemistry: Geochemistry of Non-traditional Stable Isotopes. Washington D C: The Mineralogical Society of America, 2004. 133-152

7 Baker J, Peate $\mathrm{D}$, Waight $\mathrm{T}$, et al. $\mathrm{Pb}$ isotopic analysis of standards and samples using a ${ }^{207} \mathrm{~Pb}-{ }^{204} \mathrm{~Pb}$ double spike and thallium to correct for mass bias with a double-focusing MC-ICP-MS. Chem Geol, 2004, 211: $275-303$

8 Hirata T. Lead isotopic analyses of NIST standard reference materials using multiple collector inductively coupled plasma mass spectrometry coupled with a modified external correction method for mass discrimination effect. Analyst, 1996, 121: 1407-1411

9 Halliday A N, Lee D C, Christensen J N, et al. Applications of multiple collector-ICPMS to cosmochemistry, geochemistry, and paleoceanography. Geochim Cosmochim Acta, 1998, 62: 919-940

10 Shaheen M, Fryer B J. Improving the analytical capabilities of femtosecond laser ablation multicollector ICP-MS for high precision $\mathrm{Pb}$ isotopic analysis: The role of hydrogen and nitrogen. J Anal Atom Spectrom, 2010, 25: 1006-1013

11 Longerich H P, Fryer B J, Strong D F. Determination of lead isotope ratios by inductively coupled plasma-mass spectrometry (ICP-MS). Spectrochim Acta B, 1987, 42: 39-48

12 Rehkämperab M, Halliday A N. Accuracy and long-term reproducibility of lead isotopic measurements by multiple-collector inductively coupled plasma mass spectrometry using an external method for correction of mass discrimination. Int J Mass Spectrom, 1998, 181: 123-133

13 Thirlwall M F. Multicollector ICP-MS analysis of Pb isotopes using a ${ }^{207} \mathrm{~Pb}-{ }^{204} \mathrm{~Pb}$ double spike demonstrates up to $400 \mathrm{ppm} / \mathrm{amu}$ systematic 
errors in Tl-normalization. Chem Geol, 2002, 184: 255-279

14 White $\mathrm{W}$ M, Albarède F, Télouk $\mathrm{P}$. High-precision analysis of $\mathrm{Pb}$ isotope ratios by multi-collector ICP-MS. Chem Geol, 2000, 167: 257-270

15 Woodhead J. A simple method for obtaining highly accurate $\mathrm{Pb}$ isotope data by MC-ICP-MS. J Anal Atom Spectrom, 2002, 17: 1381- 1385

16 Rehkamper M, Mezger K. Investigation of matrix effects for $\mathrm{Pb}$ isotope ratio measurements by multiple collector ICP-MS: Verification and application of optimized analytical protocols. J Anal Atom Spectrom, 2000, 15: 1451-1460

17 Belshaw N S, Freedman P A, O'Nions R K, et al. A new variable dispersion double-focusing plasma mass spectrometer with performance illustrated for $\mathrm{Pb}$ isotopes. Int J Mass Spectrom, 1998, 181: 51-58

18 Ortega G S, Pecheyran C, Berail S, et al. A fit-for purpose procedure for lead isotopic ratio determination in crude oil, asphaltene and kerogen samples by MC-ICPMS. J Anal Atom Spectrom, 2012, 27: 1447-1456

19 Fernández B, Claverie F, Pécheyran C, et al. Direct analysis of solid samples by fs-LA-ICP-MS. TrAC-Trend Anal Chem, 2007, 26: 951966

20 Koch J, Günther D. Review of the state-of-the-art of laser ablation inductively coupled plasma mass spectrometry. Appl Spectrosc, 2011, 65: 155-162

21 Russo R E, Mao X, Gonzalez J J, et al. Femtosecond laser ablation ICP-MS. J Anal Atom Spectrom, 2002, 17: 1072-1075

22 Shaheen M, Gagnon J E, Yang Z, et al. Evaluation of the analytical performance of femtosecond laser ablation inductively coupled plasma mass spectrometry at $785 \mathrm{~nm}$ with glass reference materials. J Anal Atom Spectrom, 2008, 23: 1610-1621

23 Horn I, von Blanckenburg F, Schoenberg R, et al. In situ iron isotope ratio determination using UV-femtosecond laser ablation with application to hydrothermal ore formation processes. Geochim Cosmochim Acta, 2006, 70: 3677-3688

24 Steinhoefel G, Horn I, von Blanckenburg F. Matrix-independent Fe isotope ratio determination in silicates using UV femtosecond laser ablation. Chem Geol, 2009, 268: 67-73

25 Jochum K P, Stoll B, Herwig K, et al. Lead isotope ratio measurements in geological glasses by laser ablation-sector field-ICP mass spectrometry (LA-SF-ICPMS). Int J Mass Spectrom, 2005, 242: 281289

26 Pettke T, Oberli F, Audetat A, et al. Quantification of transient signals in multiple collector inductively coupled plasma mass spectrometry: accurate lead isotope ratio determination by laser ablation of individual fluid inclusions. J Anal Atom Spectrom, 2011, 26: 475-492

27 Fontaine G H, Hattendorf B, Bourdon B, et al. Effects of operating conditions and matrix on mass bias in MC-ICPMS. J Anal Atom
Spectrom, 2009, 24: 637-648

28 Souders A K, Sylvester P J. Accuracy and precision of non-matrixmatched calibration for lead isotope ratio measurements of lead-poor minerals by LA-MC-ICPMS. J Anal Atom Spectrom, 2010, 25: 975988

29 Resano M, Marzo M P, Alloza R, et al. Laser ablation single-collector inductively coupled plasma mass spectrometry for lead isotopic analysis to investigate evolution of the Bilbilis mint. Anal Chim Acta, 2010, 677: 55-63

30 Kemp A I S, Foster G L, Scherstén A, et al. Concurrent Pb-Hf isotope analysis of zircon by laser ablation multi-collector ICP-MS, with implications for the crustal evolution of Greenland and the Himalayas. Chem Geol, 2009, 261: 244-260

31 Woodhead J D, Hergt J M. Strontium, Neodymium and Lead Isotope Analyses of NIST Glass Certified Reference Materials: SRM 610, 612, 614. Geostandard Newslett, 2001, 25: 261-266

32 Jochum K P, Wilson S A, Abouchami W, et al. GSD-1G and MPI-DING reference glasses for in situ and bulk isotopic determination. Geostand Geoanal Res, 2011, 35: 193-226

33 Jochum K P, Pfänder J, Woodhead J D, et al. MPI-DING glasses: New geological reference materials for in situ $\mathrm{Pb}$ isotope analysis. Geochem Geophys Geosyst, 2005, 6: Q10008

34 Jochum K P, Willbold M, Raczek I, et al. Chemical Characterisation of the USGS Reference Glasses GSA-1G, GSC-1G, GSD-1G, GSE1G, BCR-2G, BHVO-2G and BIR-1G Using EPMA, ID-TIMS, IDICP-MS and LA-ICP-MS. Geostand Geoanal Res, 2005, 29: 285-302

$35 \mathrm{Hu}$ M-Y, Fan X-T, Stoll B, et al. Preliminary characterisation of new reference materials for microanalysis: Chinese geological standard glasses CGSG-1, CGSG-2, CGSG-4 and CGSG-5. Geostand Geoanal Res, 2011, 35: 235-251

36 Chen K Y, Yuan H L, Bao Z A, et al. Accurate and precise in situ determination of lead isotope ratios in NIST, USGS, MPI-DING and CGSG reference glasses using femtosecond laser ablation MCICPMS. Geostand Geoanal Res, 2013, doi: 10.1111/j.1751-908x.2013. 00223.x

37 Zong C L, Yuan H L, Dai M N. A feasibility study on chemical separation of $\mathrm{Pb}, \mathrm{Sr}$ and $\mathrm{Nd}$ from the same single dissolution of geological sample (in Chinese). Rock Miner Anal, 2012, 31: 945-949

38 Zhang J L, Yuan H L, Gao S, et al. Efficient acid leaching of geological samples for lead isotope analysis (in Chinese). Earth Sci-J Chin Uni Geosci, 2008, 33: 46-56

39 Jochum K P, Brueckner S M. Reference materials in geoanalytical and environmental research-Review for 2006 and 2007. Geostand Geoanal Res, 2008, 32: 405-452

40 Jochum K P, Nohl U, Herwig K, et al. GeoReM: A new geochemical database for reference materials and isotopic standards. Geostand Geoanal Res, 2005, 29: 333-338

Open Access This article is distributed under the terms of the Creative Commons Attribution License which permits any use, distribution, and reproduction in any medium, provided the original author(s) and source are credited. 